\title{
Fidelity in sensory integration intervention research.
}

\author{
L Diane Parham \\ University of Southern California \\ Ellen S. Cohn \\ Boston University \\ Susan Spitzer \\ University of Southern California \\ Jane A. Koomar \\ Occupational Therapy Associates \\ Lucy Jane Miller \\ University of Colorado at Denver \\ Follow this and additional works at: https://jdc.jefferson.edu/otfp \\ see rartof the forcupational The trapy Commons \\ Let us know how access to this document benefits you
}

\section{Recommended Citation}

Parham, L Diane; Cohn, Ellen S.; Spitzer, Susan; Koomar, Jane A.; Miller, Lucy Jane; Burke, Janice P; Brett-Green, Barbara; Mailloux, Zoe; May-Benson, Teresa A.; Roley, Susanne Smith; Schaaf, Roseann C.; Schoen, Sarah A.; and Summers, Clare A., "Fidelity in sensory integration intervention research." (2007). Department of Occupational Therapy Faculty Papers. Paper 25. https://jdc.jefferson.edu/otfp/25

This Article is brought to you for free and open access by the Jefferson Digital Commons. The Jefferson Digital Commons is a service of Thomas Jefferson University's Center for Teaching and Learning (CTL). The Commons is a showcase for Jefferson books and journals, peer-reviewed scholarly publications, unique historical collections from the University archives, and teaching tools. The Jefferson Digital Commons allows researchers and interested readers anywhere in the world to learn about and keep up to date with Jefferson scholarship. This article has been accepted for inclusion in Department of Occupational Therapy Faculty Papers by an authorized administrator of the Jefferson Digital Commons. For more information, please contact: JeffersonDigitalCommons@jefferson.edu. 


\section{Authors}

L Diane Parham, Ellen S. Cohn, Susan Spitzer, Jane A. Koomar, Lucy Jane Miller, Janice P Burke, Barbara Brett-Green, Zoe Mailloux, Teresa A. May-Benson, Susanne Smith Roley, Roseann C. Schaaf, Sarah A.

Schoen, and Clare A. Summers 


\title{
Fidelity in Sensory Integration Intervention Research
}

\author{
L. Diane Parham, Ellen S. Cohn, Susan Spitzer, Jane A. Koomar, \\ Lucy Jane Miller, Janice P. Burke, Barbara Brett-Green, Zoe Mailloux, \\ Teresa A. May-Benson, Susanne Smith Roley, Roseann C. Schaaf, \\ Sarah A. Schoen, Clare A. Summers
}

KEY WORDS

- fidelity

- intervention

- research

- sensory integration

L. Diane Parham, PhD, OTR/L, FAOTA, is Associate Professor, Division of Occupational Science and Occupational Therapy, University of Southern California, 1540 Alcazar Street-CHP 133, Los Angeles, CA 90089; Lparham@usc.edu.

Ellen S. Cohn, ScD, OTR/L, FAOTA, is Clinical Associate Professor, Boston University, Sargent College of Health and Rehabilitation Sciences, Boston.

Susan Spitzer, PhD, OTR/L, is Adjunct Assistant Professor, University of Southern California; and in private practice, Pasadena, CA.

Jane A. Koomar, PhD, OTR/L, FAOTA, is Owner and Executive Director, Occupational Therapy AssociatesWatertown, P.C.; and Board President, The SPIRAL Foundation, Watertown, MA.

Lucy Jane Miller, PhD, OTR, FAOTA, is Associate Clinical Professor, Departments of Rehabilitation Medicine and Pediatrics, University of Colorado at Denver and Health Sciences Center; Director, Sensory Therapies and Research (STAR) Center; and Director, KID Foundation Greenwood Village, CO.

Janice P. Burke, PhD, OTR/L, FAOTA, is Professor and Chair, Department of Occupational Therapy; and Dean, Jefferson School of Health Professions, Thomas Jefferson University, Philadelphia.

Barbara Brett-Green, PhD, is Assistant Professor, University of Colorado at Denver and Health Sciences Center; and Senior Researcher, KID Foundation, Greenwood Village, CO

Zoe Mailloux, MA, OTR/L, FAOTA, is Director of Administration, Pediatric Therapy Network, Torrance, CA.

Teresa A. May-Benson, ScD, OTR/L, is Research Director, The SPIRAL Foundation; and Clinical Specialty Director, Occupational Therapy Associates, Watertown, MA.

Susanne Smith Roley, MS, OTR/L, FAOTA, is Project Director, USC/WPS Comprehensive Program in Sensory Integration, University of Southern California, Los Angeles.

Roseann C. Schaaf, PhD, OTR/L, FAOTA, is Associate Professor, Vice Chair, and Director of Graduate Studies, Department of Occupational Therapy, Thomas Jefferson University, Philadelphia.

Sarah A. Schoen, PhD, OTR, is Clinical Instructor, University of Colorado at Denver and Health Sciences Center; Director of Occupational Therapy, STAR Center; and Senior Researcher, KID Foundation, Greenwood Village, CO.

Clare A. Summers, MA, OTR, is Occupational Therapist, The Children's Hospital, Denver, CO.
OBJECTIVE. We sought to assess validity of sensory integration outcomes research in relation to fidelity (faithfulness of intervention to underlying therapeutic principles).

METHOD. We identified core sensory integration intervention elements through expert review and nominal group process. Elements were classified into structural (e.g., equipment used, therapist training) and therapeutic process categories. We analyzed 34 sensory integration intervention studies for consistency of intervention descriptions with these elements.

RESULTS. Most studies described structural elements related to therapeutic equipment and interveners' profession. Of the 10 process elements, only 1 (presentation of sensory opportunities) was addressed in all studies. Most studies described fewer than half of the process elements. Intervention descriptions in $35 \%$ of the studies were inconsistent with one process element, therapist-child collaboration.

CONCLUSION. Validity of sensory integration outcomes studies is threatened by weak fidelity in regard to therapeutic process. Inferences regarding sensory integration effectiveness cannot be drawn with confidence until fidelity is adequately addressed in outcomes research.

Parham, L. D., Cohn, E. S., Spitzer, S., Koomar, J. A., Miller, L. J., Burke, J. P., et al. (2007). Fidelity in sensory integration intervention research. American Journal of Occupational Therapy, 61, 216-227.

ntervention based on sensory integration theory (Ayres, 1972b) is widely used among occupational therapists working with various children with developmental, learning, and behavioral problems (Case-Smith \& Miller, 1999; National Board for Certification in Occupational Therapy, 2004; Roley, Blanche, \& Schaaf, 2001; Spitzer, Roley, Clark, \& Parham, 1996; Watling, Deitz, Kanny, \& McLaughlin, 1999). Furthermore, a body of research exists that addresses outcomes, efficacy, or effectiveness of occupational therapy using a sensory integration approach (OT-SI). Daems (1994), for example, compiled reviews of 57 outcomes studies published between 1972 and 1992 that evaluated intervention purportedly based on sensory integration theory. More recently, Miller (2003) reported finding more than 80 articles that address sensory integration outcomes.

Despite the availability of outcomes studies published over the past 30 years, evidence of the effectiveness of this intervention remains inconclusive. Moreover, controversy over the effectiveness of sensory integration intervention remains heated, with advocates (Burns, 1988; Cermak, 1988; Clark \& Primeau, 1988; Kimball, 1988; Miller, 2003; Ottenbacher, 1988) arguing as passionately as critics (Arendt, MacLean, \& Baumeister, 1988; Hoehn \& Baumeister, 1994; Shaw, 2002).

The status of the research presents a dilemma for occupational therapists who strive to provide evidence-based, family-centered practice. Therapists may feel conflicted as they observe improved quality of life for children and their families after intervention yet are unable to offer definitive research to support their practice based on sensory integration principles. The dilemma is heightened when families request OT-SI, but funding sources or other professionals demand unequivocal evidence of its effectiveness. 
The lack of definitive research support is related to the methodological challenges of conducting intervention effectiveness research (Cermak \& Henderson, 1989, 1990; Miller, 2003; Ottenbacher, 1991; Spitzer et al., 1996). These challenges are compounded when the intervention in question involves dynamic interactional processes that are custom-designed for the unique needs of the recipient.

One set of methodological challenges involves the selection of outcome measures. For example, outcome instruments may be insensitive to change, incongruent with the underlying theoretical principles or expected outcomes, irrelevant to participants' daily lives, or unrelated to consumers' perspectives (Cermak \& Henderson, 1989, 1990; Cohn, 2001; Cohn \& Cermak, 1998). Other methodological challenges involve adequate selection and description of recipients of the intervention, design of studies to include random assignment to alternative interventions, adequate sample sizes for statistical power, and operationalization of the intervention so that is it replicable and faithful to the underlying assumptions and philosophy and theoretical principles (Miller \& Kinnealey, 1993). This latter challenge requires careful examination and specification of the fundamental principles and strategies that guide the intervention, as well as application of a systematic method for documenting that the intervention provided was congruent with the intervention principles. This challenge is the focus of this article.

Researchers in the field of mental health have used the term fidelity to treatment when addressing the question of whether an intervention has been implemented according to its underlying theoretical principles and procedural guidelines (Kazdin, 1994; Moncher \& Prinz, 1991). The word fidelity is generally defined as faithfulness, loyalty, accuracy, and exact correspondence to the original (Oxford Encyclopedic English Dictionary, 1996). In the context of effectiveness studies, fidelity refers to the extent to which an intervention is faithful to its underlying theoretical and clinical guidelines. Related terms include adherence to treatment, treatment integrity, and specification of treatment (Teague, Bond, \& Drake, 1998; Waltz, Addis, Koerner, \& Jacobson, 1993).

In a discussion of the crucial role of randomized clinical trials (RCTs) in evaluating the effects of occupational therapy, Nelson and Mathiowetz (2004) recently asserted that "fidelity is essential in all occupational therapy RCTs" (p. 30). Fidelity can be viewed as an aspect of research validity because it addresses whether study findings reflect the underlying purpose of the study (DePoy \& Gitlin, 2005). Specifically, it may be viewed as a kind of construct validity in that it addresses the fit between the construct of interest (an intervention philosophy, frame of reference, or set of intervention principles) and the way it is operationalized (the intervention procedures that are delivered in the study).

This article seeks to assess the validity of existing sensory integration outcomes research with regard to fidelity. We aim specifically to describe the consistency with which intervention descriptions in sensory integration outcomes studies adhere to core elements of sensory integration intervention that are described in the theoretical and clinical literature, as well as the extent to which researchers have considered and systematically examined fidelity in these studies. The research questions that guided this inquiry were

- What are the core elements of sensory integration intervention?

- In published sensory integration outcomes studies, to what extent are descriptions of sensory integration intervention consistent with the core elements of sensory integration intervention?

- In these studies, to what extent have researchers systematically evaluated fidelity to plan, deliver, and monitor the intervention?

- In the studies, to what extent have researchers considered fidelity in their interpretations of results?

This description of the state of fidelity in sensory integration research will be valuable in two ways: (a) to evaluate inferences that can be made from the existing body of research and (b) to identify whether some aspects of fidelity need to be strengthened in future research. It is hoped that this second point will contribute to the validity of future research and thereby strengthen the inferences that can be drawn from the research.

\section{Evaluation of Fidelity}

The concern with fidelity emerged from criticisms of early psychotherapy effectiveness research. Eysenck (1952), in a landmark article, argued that the vagueness of psychotherapy treatment descriptions in early research on this intervention precluded drawing any conclusions regarding its effectiveness. Eysenck's article launched several lines of research from which definitive guidelines for fidelity methods and tools emerged.

The systematic evaluation of fidelity is crucial to ensure that the intervention under study can be replicated by other researchers and clearly differentiated from other types of intervention. Thus, it is important not only to describe the intervention thoroughly and to identify specific features that differentiate it from alternative interventions but also to develop a procedure by which the fidelity of intervention can be evaluated and monitored in the course of an effectiveness study. Fidelity instruments used in such procedures typically are tools that raters score while 
observing intervention or while interviewing therapists or recipients of intervention.

\section{Key Elements of a Fidelity Evaluation}

The evaluation of fidelity entails systematic, ongoing documentation of the delivery of intervention. Both structural and process elements of intervention should be addressed. Structural elements address the more directly observable, easily quantified characteristics of the intervention program and environment, such as number of recipients and interveners who participate in each intervention session, length of time of sessions, professional training of therapist, and presence of specific environmental features.

Process elements are more difficult to quantify, because they address dynamic qualities of the intervention that often are not directly observable and are usually more challenging to measure. These include elements such as quality of the therapeutic relationship (often called therapeutic alliance) and the extent to which critical treatment events occur during a given session (sometimes referred to as treatment dosage) (Burgio et al., 2001).

\section{Uses of Fidelity Procedures}

The primary uses of fidelity procedures in effectiveness studies are twofold. First, they ensure treatment integrity or representativeness; that is, assurance that the treatment being studied is delivered in a way that accurately reflects the underlying intervention principles. Second, they enable treatment differentiation; that is, precise identification of the elements that distinguish particular treatments as well as the elements that different treatments share. Treatment differentiation is desirable because ultimately it may make it possible to identify the critical ingredients that are responsible for the demonstrated effectiveness of a given intervention compared to an alternative intervention. Therefore, evaluation of fidelity is critical in interpreting the results of effectiveness studies.

Secondary uses of fidelity procedures include providing a mechanism for communication about the core characteristics of various interventions and training professionals in particular intervention methods (Bond, Evans, Salyers, Williams, \& Kim, 2000). Fidelity tools also can be used to maintain the quality and consistency of treatment over time, which may be particularly valuable to intervention researchers striving to relate levels of treatment adherence to outcomes (Kazdin, 1997).

\section{Fidelity Evaluation and Manualization of Intervention}

Experts generally agree that manualization of treatment is required to ensure treatment adherence in an effectiveness study. Manualization refers to development of a treatment procedural manual for use in a clinical trial to enhance fidelity (Burgio et al., 2001; DePoy \& Gitlin, 2005). In a treatment manual, the intervention being tested must be described as precisely as possible so that interveners can be trained in a consistent and reproducible manner. Although treatment manuals should describe interventions precisely, they need not consist of a rigid or confining "cookbook" of techniques (Luborsky \& DeRubeis, 1984).

Intervention manualization and fidelity instruments are necessary to establish treatment integrity and to verify that the intervention was delivered as intended using empirical measures. Without evidence of treatment fidelity, conclusions about efficacy or effectiveness of treatment cannot be made with confidence (Burgio et al., 2001).

\section{Fidelity in Sensory Integration Effectiveness Studies}

Fidelity in studies of sensory integration-based intervention has not previously been scrutinized. To begin the process of describing the state of fidelity in sensory integration intervention research, we extracted core elements of intervention from the sensory integration theoretical literature. We then used these elements to conduct a content analysis of the extent to which published sensory integration outcomes studies demonstrated fidelity to sensory integration intervention principles. We also evaluated researchers' attention to fidelity in planning, delivering, and monitoring sensory integration-based interventions as well as to interpreting results.

\section{Key Elements of Sensory Integration Intervention}

Our first step was to identify the key literature that describes the theoretical and pragmatic guidelines for occupational therapy using a sensory integration approach to intervention. Approximately 10 experts in sensory integration, from across the United States, met as a group and reached a consensus in the selection of 11 publications that served as key sensory integration literature (Ayres, 1972b, 1979; Bundy, 2002; Bundy \& Koomar, 2002; Kimball, 1999; Koomar \& Bundy, 2002; Mailloux \& Burke, 1997; Miller \& Summers, 2001; Miller, Wilbarger, Stackhouse, \& Trunnell, 2002; Parham \& Mailloux, 2001; Spitzer \& Roley, 2001). This group of experts then began the process of analyzing this literature to identify core elements of sensory integration intervention. We organized our analysis into two main domains: structural preparation for intervention and process of intervention.

The structural preparation domain addressed the environmental features of the sensory integration intervention. Our review of the literature clearly indicated that suspended 
equipment and other features of the physical environment - such as space, provisions for safety, and opportunities for exploration-are hallmarks of sensory integration intervention. Because the interdisciplinary fidelity literature emphasizes therapist competence as another important environmental feature, we also considered the qualifications and training necessary to provide the intervention (Moncher \& Prinz, 1991). Consequently, we identified and organized the structural features of sensory integration intervention into two main categories: (a) environmental design, which includes room setup and types of equipment, and (b) therapist qualifications, which include professional background, formal education, clinical experience, postprofessional training, supervision, and certification in sensory integration or in sensory integration clinical assessment.

The process of intervention domain in our analysis addressed the extent to which a therapist adheres to processoriented sensory integration principles during an intervention session with a child. Compared to the identification of the structural elements, this was a more complex and challenging process. Our goal was to extract core elements of the intervention process from the same key literature used to identify the structural components. This goal was accomplished, initially, through a nominal group process (Moore, 1987) with approximately 50 practitioners consisting of occupational therapists, physical therapists, speech and language pathologists, and early childhood specialists. The practitioners were divided into 11 groups, with approximately 4 to 5 practitioners of diverse professional backgrounds in each group. Each group reviewed one or two of the key references. Within each group, each practitioner independently reviewed the references to identify central elements of the therapeutic process in OT-SI, as designated in that literature. Group members then shared with each other the elements they had extracted from the references and grouped them to classify and prioritize them. After this nominal group process, the elements identified by all of the groups were aggregated and reorganized to yield 10 core intervention process elements. (See Table 1 for a description of the 10 core process elements.)

\section{Content Analysis of Fidelity in Sensory Integration Intervention Studies}

To determine the extent to which previous investigators attended to fidelity, our next step was to critically review the existing literature that claimed to examine outcomes of sensory integration intervention. Our review focused on whether descriptions of sensory integration intervention in the published effectiveness studies were consistent with the key intervention elements that we had extracted in the group processes described in the preceding section. Additionally, we examined whether previous investigators had included systematic evaluations of intervention fidelity and had considered fidelity issues when interpreting results.

\section{Method}

To identify pertinent studies, we conducted computerized searches of the Cumulative Index to Nursing and Allied Health Literature (CINAHL) for publications dated 1982 through September 2004 and Medline for 1996 through September 2004. Main search key words were sensory integration, sensory motor integration, and sensorimotor integration

\section{Table 1. Core Elements of Sensory Integration Intervention Process}

Core Process Elements

Provide sensory opportunities

Provide just-right challenges

Collaborate on activity choice

Guide self-organization

Support optimal arousal

Create play context

Maximize child's success

Ensure physical safety

Arrange room to engage child

Foster therapeutic alliance
Description of Therapist's Behavior and Attitude

Presents the child with opportunities for various sensory experiences, which include tactile, vestibular, and/or proprioceptive experiences; intervention involves more than one sensory modality.

Tailors activities so as to present challenges to the child that are neither too difficult nor too easy, to evoke the child's adaptive responses to sensory and praxis challenges.

Treats the child as an active collaborator in the therapy process, allowing the child to actively exert some control over activity choice; does not predetermine a schedule of activities independently of the child.

Supports and guides the child's self-organization of behavior to make choices and plan own behavior to the extent the child is capable; encourages the child to initiate and develop ideas and plans for activities.

Ensures that the therapy situation is conducive to attaining or sustaining the child's optimal level of arousal by making changes to environment or activity to support the child's attention, engagement, and comfort.

Creates a context of play by building on the child's intrinsic motivation and enjoyment of activities; facilitates or expands on social, motor, imaginative, or object play.

Presents or modifies activities so that the child can experience success in doing part or all of an activity that involves a response to a challenge.

Ensures that the child is physically safe either through placement of protective and therapeutic equipment or through the therapist's physical proximity and actions.

Arranges the room and equipment in the room to motivate the child to choose and engage in an activity.

Respects the child's emotions, conveys positive regard toward the child, seems to connect with the child, and creates a climate of trust and emotional safety. 
combined with effectiveness or efficacy. To identify appropriate articles published before 1982, as well as articles not detected by the computer searches, we reviewed the reference lists of articles identified in the literature search in addition to articles and book chapters in the authors' personal libraries for citations of other pertinent studies. To be included, studies had to be: (a) published in a professional journal in English; (b) directly measure the subjects' abilities or behaviors; and (c) report quantified outcomes of an intervention that the authors specifically stated was, or was based on, or promoted sensory integration, sensory motor integration, or sensorimotor integration. We excluded studies that did not report a quantitative measure of change in child performance or behavior. Consequently, we did not include purely qualitative descriptive case studies (such as Reeves, 1998; Schaaf, Merrill, \& Kinsella, 1987) and studies that reported adult appraisals without direct measures of child behavior (such as Cohn, 2001; Stonefelt \& Stein, 1998).

Because our purpose was to examine fidelity in studies that purported to use sensory integration, we excluded articles if the authors did not describe the intervention as addressing sensory integration. We did not include several studies that used the controlled use of vestibular, tactile, or proprioceptive stimuli because the authors did not describe their interventions as involving or targeting sensory integration (e.g., Case-Smith, 1995; Edelson, Edelson, Kerr, \& Grandin, 1999; Fertel-Daly, Bedell, \& Hinojosa, 2001; Reisman \& Gross, 1992). Furthermore, we also excluded one study (Morrison \& Pothier, 1972) that was included in a past meta-analysis of sensory integration intervention (Vargas \& Camilli, 1999) because neither the key words nor the descriptions of intervention in this study mentioned sensory integration.

As a result of the selection process, we identified 70 articles that met our criteria. Most of these articles were published in the United States in occupational therapy journals, but some were published outside the United States or in journals not dedicated to occupational therapy. We found that some articles presented different analyses of data from the same sample of research subjects receiving the same intervention. In such cases, we grouped the articles together to represent one study, as our focus was on the fidelity of distinct intervention studies. Accordingly, we identified 61 different studies.

Next, we examined the 61 studies to identify those in which a purportedly "pure" sensory integration intervention was provided to preschool or elementary school-age children (the age groups for whom sensory integration intervention principles originally were designed). This process yielded 34 studies. The remaining 27 studies either combined sensory integration intervention with another intervention such as neurodevelopmental treatment, or they provided sensory integration intervention to infants, adolescents, or adults (age groups for whom sensory integration intervention procedures originally were not designed). The characteristics of the interventions and study samples in this second group were likely to necessitate the modification of the key sensory integration intervention principles. Therefore, in this article, we present results for the 34 studies whose purpose was to provide a discrete sensory integration intervention to preschool or elementary school-age children. The articles we reviewed to analyze the 34 core studies are identified in the Appendix. Note that because some studies generated more than one article, the Appendix contains more than 34 articles.

\section{Results}

Consistency with key elements of sensory integration intervention. We conducted our initial content analysis of the selected 34 core studies by scrutinizing each article for descriptions related to the structural and process elements of intervention. This process involved documenting in tables the articles' contents with respect to each of the structural and process intervention elements. When the primary reviewer was unsure of how to classify an article on a particular element, or when other authors questioned a detail in a table, the first and third authors discussed the problem until a resolution was agreed on. The first, second, and fourth authors jointly tabulated the frequencies and percentages with which each intervention element was reported in the tables. Frequencies and percentages were recalculated by the third author to ensure accuracy.

Table 2 summarizes the percentages of the 34 studies that included structural and process elements in their descriptions of sensory integration intervention. The majority of the intervention descriptions addressed two structural elements: interveners' professional backgrounds and types of therapeutic equipment used in the interventions. The most commonly specified types of therapeutic equipment mentioned were tactile materials, suspended equipment, and scooter boards. Almost all studies identified the professional backgrounds of the people administering the intervention, which usually were occupational therapy, but most did not mention specialty training. Fidelity is enhanced when the specialty training of the therapist is assured, because this ensures that the therapist has had extensive formal instruction in the intervention's principles and their clinical applications.

With respect to the process elements of intervention summarized in Table 2, it is not surprising that researchers described the use of sensory strategies in $100 \%$ of these 
Table 2. Percentages of Studies Describing Elements of Intervention

\begin{tabular}{lc}
\hline Structural Elements & $\%$ \\
\hline Professional background of interveners & 94 \\
Type of therapeutic equipment & 65 \\
Clinical experience of interveners & 35 \\
Room setup & 26 \\
Supervision of interveners & 21 \\
Postprofessional sensory integration training of interveners & 18 \\
SIPT or SCSIT Certification & 18 \\
Formal education of interveners & 15 \\
\hline Process Elements & \\
\hline Presents sensory opportunities & 100 \\
Presents challenges to elicit adaptive responses & 38 \\
Supports child's self-organization of behavior & 35 \\
Collaborates with child in activity choices & 26 \\
Creates a play context & 15 \\
Helps child maintain optimal arousal & 12 \\
Maximizes child's experience of success & 9 \\
Ensures child's safety & 9 \\
Arranges room to entice engagement & 6 \\
\hline
\end{tabular}

Note. $N$ = 34 studies. SIPT = Sensory Integration \& Praxis Tests (Ayres,

1989); SCSIT = Southern California Sensory Integration Tests (Ayres, 1972c).

intervention studies, because the therapeutic use of sensory input is a hallmark of sensory integration intervention. No other process-oriented intervention element was described in most of the articles. However, each process element was described in a minimum of $2(6 \%)$ studies. No study authors described their intervention as using all 10 of the process-oriented sensory integration elements that we identified. Furthermore, most researchers provided descriptions that reflected fewer than half of these sensory integration elements. Two studies provided descriptive information that matched 5 of the 10 intervention process elements (Allen $\&$ Donald, 1995; Linderman \& Stewart, 1999). In 2 studies, 6 elements were described (Horowitz, Oosterveld, \& Adrichem, 1993; Wilson, Kaplan, Fellowes, Grunchy, \& Faris, 1992). The largest number of process elements was reported by Kinnealey (1998), whose single-case report described the intervention with sufficient detail to reflect 7 elements.

In some studies, the description of methods indicated that the intervention procedures were inconsistent with the core process elements of sensory integration intervention that we identified. Twelve studies (35\%) described treatment activities as being predetermined by the therapist or researcher rather than emerging dynamically through therapist-child collaboration. For example, in the Humphries, Wright, McDougall, and Vertes (1990) study, therapists were asked to adhere to a list of predesignated activities that were acceptable for inclusion in the sensory integration intervention sessions. Some studies even specified a particular sequence of activities, or amount of time to spend on each activity, for each session. In one study (Mason \& Iwata, 1990), the sensory integration intervention consisted of the exclusive use of several pieces of equipment to provide sensory stimulation in a therapy room. The research design of this study did not permit therapist-child interaction as a therapeutic strategy. The therapist was present in the room to monitor the child's safety but did not otherwise interact with the child, to allow the child to have continuous access to sensory stimulation without the confounding effect of "social stimulation" (p. 364). Apparently, the researchers assumed that sensory integration intervention consisted of sensory stimulation only and that the therapist-child relationship was not intrinsic to the intervention.

Use of procedures to evaluate fidelity. Ottenbacher (1991) noted that "the description of the treatment, the training of individuals responsible for implementing the intervention, and the development of procedures to monitor delivery of treatment are vital to any successful investigation" (p. 390). In our analysis of sensory integration studies, we found no study that rigorously addressed all of these aspects of fidelity evaluation. Some studies used one or two strategies to maximize or monitor fidelity, such as use of intervention manuals, supervision of interveners, and checking adherence to intervention guidelines.

Of the 34 studies, only 4 mentioned the use of an intervention manual, set of specific criteria, or protocol to guide treatment (Humphries et al., 1990; Humphries, Wright, Snider, \& McDougall, 1992; Paul et al., 2003; Polatajko, Law, Miller, Schaffer, \& Macnab, 1991). In 5 studies, researchers used various informal checks of the intervention that were not quantified (e.g., observation, supervision of therapists, or therapist's documentation of activities).

Only one study described the use of a quantitatively scored fidelity instrument to ensure that the interventions were being delivered as planned and to evaluate the impact of fidelity on study results (Humphries et al., 1992; Humphries, Snider, \& McDougall, 1993, 1997). These researchers differentiated sensory integration therapy from perceptual-motor therapy using a categorization of activities used in each approach. Sensory integration therapy was defined as the use of selected activities that provided tactile, vestibular, and proprioceptive experiences while encouraging adaptive responses. Activities designated for sensory integration therapy included use of equipment and materials such as net swings, trapezes, therapy balls, blankets, scooter boards, and ramps. Perceptual-motor therapy provided specific motor training activities, including jumping jacks, skipping, hopping, and tumbling, to remediate specific weaknesses in gross and fine motor skill. Based on ratings assigned by external observers of therapy sessions, the researchers found high adherence to intervention plans during the study for both the sensory integration and the perceptual-motor interventions. This study is outstanding 
in that the researchers systematically attempted to differentiate sensory integration-based intervention from an alternative treatment using an instrument to measure the fidelity of each intervention. Although their narrative descriptions of sensory integration therapy incorporated 4 of the 10 intervention process elements, their fidelity instrument was limited in that it focused almost exclusively on structural elements, that is, the presence or absence of particular activities and equipment.

Use of fidelity data to interpret research results. Consideration of fidelity should inform researchers' interpretations of results (Moncher \& Prinz, 1991). Our analysis of sensory integration intervention studies showed that researchers seldom considered fidelity in the discussion sections of their articles. We found only 3 studies in which the discussion of results addressed fidelity issues (Kimball, 1990; Polatajko et al., 1991; Wilson et al., 1992).

Although Wilson et al. (1992) provided an exemplary description of sensory integration intervention that included a relatively large number of principles (6), they acknowledged that a limitation of their study was that they "strived to make conditions ideal (no overlap of treatment methods to ensure 'pure' forms of treatment. ... These procedures may have placed undue constraints on the SI treatment, preventing a group difference from being found" (p. 31). These authors did not mention that the lack of fidelity instruments to monitor adherence to treatment principles may also have influenced their results.

In the study that used the most well-developed plan for monitoring and evaluating fidelity (Humphries et al., 1992, 1993), the researchers did not explicitly discuss fidelity's impact on the results, presumably because they reported high levels of adherence to intervention guidelines for the sensory integration intervention and the alternative intervention. However, as noted earlier, the fidelity instrument used in this study addressed primarily the structural features of specific equipment and activities, with little attention to the measurement of process features of intervention.

\section{Discussion}

Our investigation of intervention fidelity in the sensory integration outcomes literature indicated that (a) the descriptions of interventions being evaluated usually did not fully address the key structural and process elements of sensory integration intervention and in some cases actually seemed to be in opposition to certain principles, (b) researchers have rarely documented the fidelity of sensory integration interventions in a systematic and thorough manner, and (c) researchers have seldom addressed the potential influence of fidelity breaches on results. These findings suggest that researchers should carefully consider the extent to which interventions demonstrate fidelity when identifying studies to include in reviews of sensory integration intervention outcomes and when making inferences regarding the effectiveness of this intervention.

A limitation of our study is that our identification of the key elements of sensory integration intervention depended on expert opinion for the selection of key articles in the literature review, for identification of structural elements, and for extraction of process elements of sensory integration intervention from the products of the nominal group process. Reliance on expert opinion may have biased our results. This limitation is difficult to avoid but probably was minimized by the inclusion of experts from geographically diverse areas of the United States, as well as the involvement of a large group of interdisciplinary reviewers in the nominal group process that generated the initial list of intervention ingredients.

Our analysis of the extent to which interventions identified as "sensory integration" reflected the core ingredients of sensory integration intervention depended on the thoroughness and clarity of the intervention descriptions in the published studies. It is conceivable that, in many cases, the published article did not fully describe the extent to which intervention delivery was consistent with the core sensory integration elements we identified. In fact, the studies authored by Ayres, the originator of sensory integration intervention, collectively described no more than 4 of the core sensory integration elements that we identified (Ayres, 1972a, 1972b, 1977, 1978; Ayres \& Mailloux, 1981; Ayres $\&$ Tickle, 1980). It may be that in these studies and others, the interventions were delivered in a manner that was much more consistent with the core elements than is apparent from the published descriptions.

On the other hand, our results did show that some researchers explicitly described intervention strategies that are not consistent with the core process elements. This problem is called representativeness of treatment because it constitutes a breach in the faithful representation of the intervention when treatment manuals or guidelines are developed (Kazdin, 1994). We found this problem most frequently in relation to the element that we called collaborate on activity choice. In contradiction to this element, $12(35 \%)$ of the studies we reviewed described intervention activities as being specified or scheduled by the therapist or researcher in advance of therapy sessions. This feature very likely compromised the enactment of other intervention process elements that we considered to be core, such as guiding the child's self-organization, offering the just-right challenge, and supporting optimal arousal, which all require a high degree of responsiveness 
to the child's changing states, interests, competencies, and challenges.

We found only one study that used a combination of an intervention manual, a fidelity instrument, and a method for analyzing the potential effects of fidelity on results (Humphries et al., 1992). Interestingly, in this study and in others (e.g., Wilson et al., 1992), the researchers seemed to assume that the intervention guidelines for the sensory integration intervention should not overlap at all with the alternative intervention being tested. This view is not shared by methodological experts on treatment fidelity, who acknowledge that different interventions often, and appropriately, share common features. For example, one fidelity scale designed for use in a clinical trial of familybased interventions contained (a) items unique to a new intervention, (b) items unique to the alternative intervention, (c) items common to both interventions, and (d) "non-specific" items prescribed by virtually every psychotherapeutic model (Hogue, Liddle, \& Rowe, 1996). With respect to the latter type of item, therapeutic alliance may be viewed as a critical ingredient in many different treatment models (Kazdin, 1997).

\section{Implications}

The development of fidelity instruments that measure adherence to underlying intervention principles is overdue in occupational therapy effectiveness research. Miller (2003) has argued that the lack of attention to fidelity issues in sensory integration effectiveness research compromises the extent to which conclusions can be drawn regarding the effectiveness of OT-SI. Results of this investigation provide quantitative evidence that supports Miller's assertion.

Our findings underscore the need for a fidelity instrument that could be used in sensory integration effectiveness research to document how faithful the delivered intervention is to the underlying elements of sensory integration intervention and how consistently it is delivered. The key structural and process elements of sensory integration intervention that we identified in this study could be used to organize such a fidelity instrument. The availability of a well-developed fidelity tool that measures process as well as structural elements might increase the likelihood that interventions called "sensory integration" in the effectiveness literature are delivered in a way that accurately represents sensory integration intervention. This could be accomplished through the use of intervention manuals that specify guidelines for implementing the core elements, in conjunction with compatible fidelity tools to monitor and evaluate adherence of intervention to core principles. The authors of this article have begun to develop such a fidelity instru- ment, as well as a companion intervention manual; a pilot fidelity instrument is now undergoing revision guided by reliability and validity assessments. Details regarding this instrument are beyond the scope of this article and will be reported in future articles.

Use of a sound sensory integration fidelity instrument in effectiveness research might contribute to a better understanding of which elements of sensory integration intervention are the crucial ingredients that lead to desired outcomes. It is conceivable that analysis of fidelity data for each of the core sensory integration elements might indicate that strong adherence to certain elements is particularly associated with desirable outcomes. Such findings might inspire refinements to the intervention so that beneficial elements are maximized, ultimately leading to more effective intervention.

\section{Acknowledgments}

The authors gratefully acknowledge the assistance of the many people who contributed to this project, particularly Dr. Alexis Henry; the staff of Pediatric Therapy Network in Torrance, CA; the staff of Occupational Therapy Associates in Watertown, MA; The SPIRAL Foundation; Jill Jantos; Boston University students Pamela Errico, Christine Hegarty, and Emily Nielsen; and University of Southern California students Odessa Alpuerto, Gina Bongiovani Mirigliani, and Sunaina Subhagan.

\section{Appendix}

Articles Included in Content Analysis: Sensory Integration Outcomes Studies of Children

Allen, S., \& Donald, M. (1995). The effect of occupational therapy on the motor proficiency of children with motor/learning difficulties: A pilot study. British Journal of Occupational Therapy, 58, 385-391.

Ayres, A. J. (1972). Improving academic scores through sensory integration. Journal of Learning Disabilities, 5, 338-343.

Ayres, A. J. (1977). Effect of sensory integrative therapy on the coordination of children with choreoathethoid movements. American Journal of Occupational Therapy, 31, 291-293.

Ayres, A. J. (1978). Learning disabilities and the vestibular system. Journal of Learning Disabilities, 11, 30-41.

Ayres, J., \& Mailloux, Z. (1981). Influence of sensory integration procedures on language development. American Journal of Occupational Therapy, 35, 383-390.

Ayres, A. J., \& Tickle, L. S. (1980). Hyper-responsivity to touch and vestibular stimuli as a predictor of positive response to sensory integration procedures by autistic children. American Journal of Occupational Therapy, 34, 375-381.

Bullock, M. I., \& Watter, P. (1978). A study of the effectiveness of physiotherapy in the management of young children with 
minimal cerebral dysfunction. Australian Journal of Physiotherapy, 24, 111-119.

Bumin, G., \& Kayihan, H. (2001). Effectiveness of two different sensory-integration programmes for children with spastic diplegic cerebral palsy. Disability and Rehabilitation, 23, 394-399.

Carte, E., Morrison, D., Sublett, J., Uemera, A., \& Setrakian, W. (1984). Sensory integration therapy: A trial of a specific neurodevelopmental therapy for the remediation of learning disabilities. Journal of Developmental and Behavioral Pediatrics, 5, 189-194.

Case-Smith, J., \& Bryan, T. (1999). The effects of occupational therapy and sensory integration emphasis on preschool-age children with autism. American Journal of Occupational Therapy, 53, 489-497.

DeGangi, G. A., Wietlisbach, S., Goodin, M., \& Scheiner, N. (1993). A comparison of structured sensorimotor therapy and child-centered activity in the treatment of preschool children with sensorimotor problems. American Journal of Occupational Therapy, 47, 777-786.

Densem, J. F., Nuthall, G. A., Bushnell, J., \& Horn, J. (1989). Effectiveness of a sensory integrative therapy program for children with perceptual-motor deficits. Journal of Learning Disabilities, 22, 221-229.

DePauw, K. P. (1978). Enhancing the sensory integration of aphasic students. Journal of Learning Disabilities, 11, 29-33.

Grimwood, L. M., \& Rutherford, E. M. (1980). Sensory integrative therapy as an intervention procedure with grade one "at risk" reader-A three year study. The Exceptional Child, 27, 52-61.

Horowitz, L. J., Oosterveld, W. J., \& Adrichem, R. (1993). Effectiveness of sensory integration therapy on smooth pursuits and organization time in children. Pediatrie und Grenzgebiet, 31, 331-344.

Humphries, T., Wright, M., McDougall, B., \& Vertes, J. (1990). The efficacy of sensory integration therapy for children with learning disability. Physical and Occupational Therapy in Pediatrics, 10, 1-17.

Humphries, T., Wright, M., Snider, L., \& McDougall, B. (1992). A comparison of the effectiveness of sensory integrative therapy and perceptual-motor training in treating children with learning disabilities. Journal of Developmental and Behavioral Pediatrics, 13, 31-40.

Humphries, T. W., Snider, L., \& McDougall, B. (1993). Clinical evaluation of the effectiveness of sensory integrative and perceptual motor therapy in improving sensory integrative function in children with learning disabilities. Occupational Therapy Journal of Research, 13, 163-182.

Humphries, T. W., Snider, L., \& McDougall, B. (1997). Therapists' consistency in following their treatment plans for sensory integrative and perceptual-motor therapy. American Journal of Occupational Therapy, 51, 104-112.

Jenkins, J. R., Fewell, R., \& Harris, S. R. (1983). Comparison of sensory integrative therapy and motor programming. American Journal of Mental Deficiency, 88, 221-224.

Kaplan, B. J., Polatajko, H. J., Wilson, B. N., \& Faris, P. D. (1993). Reexamination of sensory integration treatment: A combination of two efficacy studies. Journal of Learning Disabilities, 26, 342-347.
Kemmis, B. L., \& Dunn, W. (1996). Collaborative consultation: The efficacy of remedial and compensatory interventions in school contexts. American Journal of Occupational Therapy, 50, 709-717.

Kimball, J. G. (1990). Using the Sensory Integration and Praxis Tests to measure change: A pilot study. American Journal of Occupational Therapy, 44, 603-608.

Kinnealey, M. (1998). Princess or tyrant: A case report of a child with sensory defensiveness. Occupational Therapy International, 5, 293-303.

Kinnealey, M., Koenig, K. P., \& Huecker, G. E. (1999). Changes in special needs children following intensive short-term intervention. Journal of Developmental and Learning Disorders, 3, 85-103.

Law, M., Polatajko, H. J., Schaffer, R., Miller, J., \& Macnab, J. (1991). The impact of heterogeneity in a clinical trial: Motor outcomes after sensory integration therapy. Occupational Therapy Journal of Research, 11, 177-189.

Leemrijse, C., Meijer, O. G., Vermeer, A., Ader, H. J., \& Diemel, S. (2000). The efficacy of Le Bon Depart and sensory integration treatment for children with developmental coordination disorder: A randomized study with six single cases. Clinical Rehabilitation, 14, 247-259.

Linderman, T. M., \& Stewart, K. B. (1999). Sensory integrativebased occupational therapy and functional outcomes in young children with pervasive developmental disorders: A single-subject study. American Journal of Occupational Therapy, 53, 207-213.

Magrun, W. M., Ottenbacher, K., McCue, S., \& Keefe, R. (1981). Effects of vestibular stimulation on spontaneous use of verbal language in developmentally delayed children. American Journal of Occupational Therapy, 35, 101-104.

Mason, S. A., \& Iwata, B. A. (1990). Artifactual effects of sensory-integrative therapy on self-injurious behavior. Journal of Applied Behavior Analysis, 23, 361-370.

Montgomery, P., \& Richter, E. (1977). Effect of sensory integrative therapy on the neuromotor development of retarded children. Physical Therapy, 57, 799-806.

Morrison, D., \& Sublett, J. (1986). The effects of sensory integration therapy on nystagmus duration, equilibrium reactions and visual-motor integration in reading retarded children. Child: Care, Health, and Development, 12, 99-110.

Paul, S., Sinen, P., Johnson, J., Latshaw, C., Newton, J., Nelson, A., et al. (2003). The effects of a sensory motor activities protocol based on the theory of sensory integration on children diagnosed with preprimary impairments. Occupational Therapy in Health Care, 17(2), 19-34.

Polatajko, H. J., Law, M., Miller, J., Schaffer, R., \& Macnab, J. (1991). The effect of a sensory integration program on academic achievement, motor performance, and self-esteem in children identified as learning disabled: Results of a clinical trial. Occupational Therapy Journal of Research, 11, 155-176.

Schaffer-Pullan, A., Polatajko, H. J., \& Sansom, L. (1991). A sensory integrative approach for children with hearing impairment: A case study. Canadian Journal of Occupational Therapy, 58, 196-200.

Schroeder, R. H. (1982). Improvement in academic achievement through enhancement of perceptual and sensory integrative functioning. School Psychology International, 3, 97-103. 
Uyanik, M., Bumin, G., \& Kayihan, H. (2003). Comparison of different therapy approaches in children with Down syndrome. Pediatrics International, 45(1), 68-73.

Werry, J. S., Scaletti, R., \& Mills, F. (1990). Sensory integration and teacher-judged learning problems: A controlled intervention trial. Journal of Paediatric Child Health, 26, 31-35.

White, M. (1979). A first-grade intervention program for children at risk for reading failure. Journal of Learning Disabilities, 12, 26-32.

Wilson, B. N., \& Kaplan, B. J. (1994). Follow-up assessment of children receiving sensory integration treatment. Ocсupational Therapy Journal of Research, 14, 244-266.

Wilson, B. N., Kaplan, B. J., Fellowes, S., Grunchy, C., \& Faris, P. (1992). The efficacy of sensory integration treatment compared to tutoring. Physical and Occupational Therapy in Pediatrics, $12(1), 1-36$.

\section{References}

Allen, S., \& Donald, M. (1995). The effect of occupational therapy on the motor proficiency of children with motor/learning difficulties: A pilot study. British Journal of Occupational Therapy, 58, 385-391.

Arendt, R., MacLean, W. E., Jr., \& Baumeister, A. (1988). Critique of sensory integration therapy and its application in mental retardation. American Journal of Mental Retardation, 92, 401-411.

Ayres, A. J. (1972a). Improving academic scores through sensory integration. Journal of Learning Disabilities, 5, 338-343.

Ayres, A. J. (1972b). Sensory integration and learning disorders. Los Angeles: Western Psychological Services.

Ayres, A. J. (1972c). Southern California Sensory Integration tests. Los Angeles: Western Psychological Services.

Ayres, A. J. (1977). Effect of sensory integrative therapy on the coordination of children with choreoathethoid movements. American Journal of Occupational Therapy, 31, 291-293.

Ayres, A. J. (1978). Learning disabilities and the vestibular system. Journal of Learning Disabilities, 11, 30-41.

Ayres, A. J. (1979). Sensory integration and the child. Los Angeles: Western Psychological Services.

Ayres, A. J. (1989). Sensory Integration and Praxis Tests. Los Angeles: Western Psychological Services.

Ayres, J., \& Mailloux, Z. (1981). Influence of sensory integration procedures on language development. American Journal of Occupational Therapy, 35, 383-390.

Ayres, A. J., \& Tickle, L. S. (1980). Hyper-responsivity to touch and vestibular stimuli as a predictor of positive response to sensory integration procedures by autistic children. American Journal of Occupational Therapy, 34, 375-381.

Bond, G. R., Evans, L., Salyers, M. P., Williams, J., \& Kim, H. (2000). Measurement of fidelity in psychiatric rehabilitation. Mental Health Services Research, 2, 75-87.

Bundy, A. C. (2002). The process of planning and implementing intervention. In A. C. Bundy, S. J. Lane, A. G. Fisher, \& E. A. Murray (Eds.), Sensory integration: Theory and practice (2nd ed., pp. 212-225). Philadelphia: F. A. Davis.

Bundy, A. C., \& Koomar, J. A. (2002). Orchestrating intervention: The art of practice. In A. C. Bundy, S. J. Lane, A. G. Fisher, \& E. A. Murray (Eds.), Sensory integration: Theory and practice (2nd ed., pp. 242-260). Philadelphia: F. A. Davis.

Burgio, L., Corcoran, M., Lichstein, K. L., Nichols, L., Czaja, S., Gallagher-Thompson, D., et al. (2001). Judging outcomes in psychosocial interventions for dementia caregivers: The problem of treatment implementation. The Gerontologist, 41, 481-489.

Burns, Y. R. (1988). Sensory integration or the role of sensation in movement [Comment]. American Journal of Mental Retardation, 92, 412.

Case-Smith, J. (1995). The relationships among sensorimotor components, fine motor skill, and functional performance in preschool children. American Journal of Occupational Therapy, 49, 645-654.

Case-Smith, J., \& Miller, H. (1999). Occupational therapy with children with pervasive developmental disorders. American Journal of Occupational Therapy, 53, 506-513.

Cermak, S. A. (1988). Sensible integration [Comment]. American Journal of Mental Retardation, 92, 413-414.

Cermak, S. A., \& Henderson, A. (1989). The efficacy of sensory integration procedures. Sensory Integration Quarterly, 17, 1-4.

Cermak, S. A., \& Henderson, A. (1990). The efficacy of sensory integration procedures. Sensory Integration Quarterly, 18, 1-5.

Clark, F., \& Primeau, L. A. (1988). Obfuscation of sensory integration: A matter of professional predation [Comment]. American Journal of Mental Retardation, 92, 415-420.

Cohn, E. S. (2001). Parent perspectives of occupational therapy using a sensory integration approach. American Journal of Occupational Therapy, 55, 285-294.

Cohn, E. S., \& Cermak, S. A. (1998). Including the family perspective in sensory integration outcomes research. American Journal of Occupational Therapy, 52, 540-546.

Daems, J. (Ed). (1994). Reviews of research in sensory integration. Torrance, CA: Sensory Integration International.

DePoy, E., \& Gitlin, L. N. (2005). Introduction to research: Understanding and applying multiple strategies. (3rd ed.). St. Louis, MO: Elsevier Mosby.

Edelson, S. M., Edelson, M. G., Kerr, D. C. R., \& Grandin, T. (1999). Behavioral and physiological effects of deep pressure on children with autism: A pilot study evaluating the efficacy of Grandin's Hug Machine. American Journal of Occupational Therapy, 53, 145-152.

Eysenck, H. (1952). The effects of psychotherapy: An evaluation. Journal of Consulting Psychology, 16, 319-324.

Fertel-Daly, D., Bedell, G., \& Hinojosa, J. (2001). Effects of a weighted vest on attention to task and self-stimulatory behaviors in preschoolers with pervasive developmental disorders. American Journal of Occupational Therapy, 55, 629-640.

Hoehn, T. P., \& Baumeister, A. A. (1994). A critique of the application of sensory integration therapy to children with learning disabilities. Journal of Learning Disabilities, 27, 338-350.

Hogue, A., Liddle, H. A., \& Rowe, C. (1996). Treatment adherence process research in family therapy: A rationale and some practical guidelines. Psychotherapy, 33, 332-345.

Horowitz, L. J., Oosterveld, W. J., \& Adrichem, R. (1993). Effectiveness of sensory integration therapy on smooth pursuits and organization time in children. Pediatrie und Grenzgebiet, 31, 331-344. 
Humphries, T., Wright, M., McDougall, B., \& Vertes, J. (1990). The efficacy of sensory integration therapy for children with learning disability. Physical and Occupational Therapy in Pediatrics, 10, 1-17.

Humphries, T., Wright, M., Snider, L., \& McDougall, B. (1992). A comparison of the effectiveness of sensory integrative therapy and perceptual-motor training in treating children with learning disabilities. Developmental and Behavioral Pediatrics, 13, 31-40.

Humphries, T. W., Snider, L., \& McDougall, B. (1993). Clinical evaluation of the effectiveness of sensory integrative and perceptual motor therapy in improving sensory integrative function in children with learning disabilities. Occupational Therapy Journal of Research, 13, 163-183.

Humphries, T. W., Snider, L., \& McDougall, B. (1997). Therapists' consistency in following their treatment plans for sensory integrative and perceptual-motor therapy. American Journal of Occupational Therapy, 51, 104-112.

Kazdin, A. E. (1994). Methodology, design, and evaluation in psychotherapy research. In A. E. Bergin \& S. L. Garfield (Eds.), Handbook of psychotherapy and behavior change (4th ed., pp. 19-71). New York: Wiley.

Kazdin, A. E. (1997). A model for developing effective treatments: Progression and interplay of theory, research, and practice. Journal of Clinical Child Psychology, 26, 114-129.

Kimball, J. G. (1988). The emphasis is on integration, not sensory [Comment]. American Journal of Mental Retardation, 92, 423-424.

Kimball, J. G. (1990). Using the Sensory Integration and Praxis Tests to measure change: A pilot study. American Journal of Occupational Therapy, 44, 603-608.

Kimball, J. G. (1999). Sensory integration frame of reference: Postulates regarding change and application to practice. In P. Kramer \& J. Hinojosa (Eds.), Frames of reference for pediatric occupational therapy (2nd ed., pp. 169-204). Philadelphia: Lippincott Williams \& Wilkins.

Kinnealey, M. (1998). Princess or tyrant: A case report of a child with sensory defensiveness. Occupational Therapy International, 5, 293-303.

Koomar, J. A., \& Bundy, A. C. (2002). Creating direct intervention from theory. In A. C. Bundy, S. J. Lane, A. G. Fisher, \& E. A. Murray (Eds.), Sensory integration: Theory and practice (2nd ed., pp. 261-306). Philadelphia: F. A. Davis.

Linderman, T. M., \& Stewart, K. B. (1999). Sensory integrativebased occupational therapy and functional outcomes in young children with pervasive developmental disorders: A single-subject study. American Journal of Occupational Therapy, 53, 207-213.

Luborsky, L., \& DeRubeis, R. J. (1984). The use of psychotherapy treatment manuals: A small revolution in psychotherapy research style. Clinical Psychology Review, 4, 5-14.

Mailloux, Z., \& Burke, J. P. (1997). Play and the sensory integrative approach. In L. D. Parham \& L. S. Fazio (Eds.), Play in occupational therapy for children (pp. 112-125). St. Louis, MO: Mosby.

Mason, S. A., \& Iwata, B. A. (1990). Artifactual effects of sensory-integrative therapy on self-injurious behavior. Journal of Applied Behavior Analysis, 23, 361-370.
Miller, L. J. (2003). Empirical evidence related to therapies for sensory processing impairments. Communiqué, 31, 34-37.

Miller, L. J., \& Kinnealey, M. (1993). Researching the effectiveness of sensory integration. Sensory Integration Quarterly, 21, 2.

Miller, L. J., \& Summers, C. (2001). Clinical applications in sensory modulation dysfunction: Assessment and intervention considerations. In S. S. Roley, E. I. Blanche, \& R. C. Schaaf (Eds.), Understanding the nature of sensory integration with diverse populations (pp. 247-266). San Antonio, TX: Therapy Skill Builders.

Miller, L. J., Wilbarger, J. L., Stackhouse, T. M., \& Trunnell, S. L. (2002). Use of clinical reasoning in occupational therapy: The STEP-SI model of treatment of sensory modulation dysfunction. In A. C. Bundy, S. J. Lane, A. G. Fisher, \& E. A. Murray (Eds.), Sensory integration: Theory and practice (2nd ed., pp. 435-451). Philadelphia: F. A. Davis.

Moncher, F. J., \& Prinz, R. J. (1991). Treatment fidelity in outcome studies. Clinical Psychology Review, 11, 247-266.

Moore, K. M. (1987). Group techniques for idea building. Newbury Park, CA: Sage.

Morrison, D., \& Pothier, P. (1972). Two different remedial motor training programs and the development of mentally retarded pre-schoolers. American Journal of Mental Deficiency, 77, 251-258.

National Board for Certification in Occupational Therapy. (2004). A practice analysis study for entry-level occupational therapist registered and certified occupational therapy assistant practice. Occupational Therapy Journal of Research, 24 (Suppl. 1), 1-31.

Nelson, D. L., \& Mathiowetz, V. (2004). Randomized controlled trials to investigate occupational therapy research questions. American Journal of Occupational Therapy, 58, 24-34.

Ottenbacher, K. (1991). Research in sensory integration: Empirical perceptions and progress. In A. G. Fisher, E. A. Murray, \& A. C. Bundy (Eds.), Sensory integration: Theory and practice (pp. 385-399). Philadelphia: F. A. Davis.

Ottenbacher, K. J. (1988). Sensory integration-Myth, method, and imperative [Comment]. American Journal of Mental Retardation, 92, 425-426.

Oxford encyclopedic English dictionary. (3rd ed.). (1996). New York: Oxford University Press.

Parham, D., \& Mailloux, Z. (2001). Sensory Integration. In J. Case-Smith (Ed.), Occupational therapy for children (pp. 329-381). Philadelphia: Mosby.

Paul, S., Sinen, P., Johnson, J., Latshaw, C., Newton, J., Nelson, A., et al. (2003). The effects of a sensory motor activities protocol based on the theory of sensory integration on children diagnosed with preprimary impairments. Occupational Therapy in Health Care, 17, 19-34.

Polatajko, H. J., Law, M., Miller, J., Schaffer, R., \& Macnab, J. (1991). The effect of a sensory integration program on academic achievement, motor performance, and self-esteem in children identified as learning disabled: Results of a clinical trial. Occupational Therapy Journal of Research, 11, 155-176.

Reeves, G. D. (1998). Case report of a child with sensory integration dysfunction. Occupational Therapy International, 5, 304-316. 
Reisman, J. E., \& Gross, A. Y. (1992). Psychophysiological measurement of treatment effects in an adult with sensory defensiveness. Canadian Journal of Occupational Therapy, 59, 248-257.

Roley, S. S., Blanche, E. I., \& Schaaf, R. C. (Eds.) (2001). Understanding the nature of sensory integration with diverse populations. San Antonio, TX: Therapy Skill Builders.

Schaaf, R. C., Merrill, S. C., \& Kinsella, N. (1987). Sensory integration and play behavior: A case study of the effectiveness of occupational therapy using sensory integrative techniques. Occupational Therapy in Health Care, 4, 61-75.

Shaw, S. R. (2002). A school psychologist investigates sensory integration therapies: Promise, possibility, and the art of placebo. Communiqué, 31, 5-6.

Spitzer, S., \& Roley, S. S. (2001). Sensory integration revisited: A philosophy of practice. In Roley, S. S., Blanche, E. I., \& Schaaf, R. C. (Eds.), Understanding the nature of sensory integration with diverse populations (pp. 3-27). San Antonio, TX: Therapy Skill Builders.

Spitzer, S., Roley, S. S., Clark, F., \& Parham, D. (1996). Sensory integration: Current trends in the United States. Scandinavian Journal of Occupational Therapy, 3, 123-138.
Stonefelt, L. L., \& Stein, F. (1998). Sensory integration techniques applied to children with learning disabilities: An outcome study. Occupational Therapy International, 5, 252-272.

Teague, G., Bond G., \& Drake, R, (1998). Program fidelity in assertive community treatment: Development and use of a measure. American Journal of Orthopsychiatry, 68, 216-232.

Vargas, S., \& Camilli, G. (1999). A meta-analysis of research on sensory integration treatment. American Journal of Occupational Therapy, 53, 189-198.

Waltz, J., Addis, M., Koerner, K., \& Jacobson, N. S. (1993). Testing the integrity of a psychotherapy protocol: Assessing therapist adherence and competence. Journal of Consulting and Clinical Psychology, 61, 620-630.

Watling, R., Deitz, J., Kanny, E. M., \& McLaughlin, J. F. (1999). Current practice of occupational therapy for children with autism. American Journal of Occupational Therapy, 53, 498-505.

Wilson, B. N., Kaplan, B. J., Fellowes, S., Grunchy, C., \& Faris, P. (1992). The efficacy of sensory integration treatment compared to tutoring. Physical and Occupational Therapy in Pediatrics, $12(1), 1-36$.
AOTA's 2007 Annual Conference \& Expo St. Louis, Missouri Friday, April 20-Monday, April 23 March 28-Advance Registration Deadline

\section{Primary Content Areas}

- Academic Education

- Accessibility \& Environmental Modification

- Administration \& Management

- Cognition

- Developmental Disabilities

- Driver Rehabilitation \& Community Mobility

- Emerging Technologies

- Ergonomics \& Work Programs

- Feeding \& Swallowing

- Fieldwork Education

- General \& Professional Issues

- Gerontology
Close to 500 education sessions in 25 different primary content focus areas!

- Health Promotion/Wellness/Prevention

- Home \& Community Health

- International \& Cultural Issues

- Low Vision

- Measurement Development

- Mental Health

- Occupational Science

- Occupational Therapy Assistant Issues

- Physical Rehabilitation

- Private Practice/Entrepreneurship in Practice

- Public Policy-new this year!

- School System/Early Intervention

- Sensory Integration/Sensory Processing

Complete details available at www.aota.org/conference 